\title{
Limbal Vernal Keratoconjunctivitis: Clinical Characteristics and Immunoglobulin E Expression Compared with Palpebral Vernal
}

\author{
S. J. TUFT, ${ }^{*}$ J. K. G. DART* and M. KEMENY† \\ London
}

\begin{abstract}
Summary
Limbal and palpebral vernal keratoconjunctivitis (VKC) are usually considered to be different expressions of the same disease. This single centre population of 120 patients with VKC had 32 patients with limbal VKC, 54 with palpebral VKC and 34 with mixed palpebral and limbal VKC. There were higher proportions of females $(p=0.015)$ blacks, Indians and Asians $(p=0.0001)$ in the limbal group and fewer limbal patients had other atopic diseases $(p=0.03)$. The age of presentation was similar for all groups; $87 / 112$ (78 per cent) presenting before the age of 16 . The follow-up period was shorter in the limbal VKC patients $(p=0.004)$ suggesting a shorter disease course. Only one limbal VKC patient developed corneal opacities compared to fifty (47 per cent) with palpebral or mixed VKC, 24 ( 27 per cent) of whom lost vision. Tear and serum levels of total IgE and specific IgE to the major inhalent allergens cat, house dust mite and grass pollen were compared in 17 patients with palpebral or mixed VKC and ten with limbal VKC; no statistically significant differences were shown. However the significant variations in sex, racial distribution and associated atopic disease suggest that limbal VKC may be a different disease from palpebral VKC although this is not expressed in terms of IgE production.
\end{abstract}

The clinical classification of vernal keratoconjunctivitis (VKC) into limbal, palpebral and mixed types of the disease was established by Emmert in 1888 and has been widely used since. In his influential text Beigleman commented that, although the preponderance of the mixed type increased depending on the length of observation and thoroughness of the study, there were undoubtedly regional variations in the prevalence of these types. He also noted that the type of lesion, and degree of involvement, might vary considerably in different parts of the same conjunctiva; in his concluding statement on classification he suggested that these different types of VKC are different expressions of the same disease. ${ }^{1}$ Subsequent texts have concurred with this ${ }^{2-7}$ as well as supporting the view that regional and racial variations in the prevalence of the different forms of VKC exist with the limbal form predominant in blacks and the palpebral in whites. ${ }^{2.5-7}$ The implications of this for the pathogenesis of VKC have not been discussed. In this study we have examined differences in the clinical characteristics and $\operatorname{IgE}$ expression in one population of subjects with

From: *Department of Clinical Ophthalmology, Institute of Ophthalmology and Moorfields Eye Hospital. $\dagger$ Department of Allergy and Allied Respiratory Disorders, Guys Hospital.

Correspondence to: JKG Dart FRCS, Department of Clinical Ophthalmology, Moorfields Eye Hospital, City Road, London EC1V 2PD. 
VKC to evaluate whether limbal, palpebral and mixed $\mathrm{VKC}$ show evidence of variations in pathogenesis.

\section{Study Group and Methods}

\section{Subjects}

The records of all 120 patients who had attended a single clinic at Moorfields in the two years to August 1 1988, and in whom a diagnosis of VKC was made, were included. Each was classified as limbal, palpebral or mixed disease. The total numbers in each group, their age, sex, race, history of the other major atopic diseases (eczema, asthma, hayfever, perennial allergic rhinitis), the age of onset and the follow-up period were recorded.

Of these patients, 10 with limbal VKC and 17 with palpebral or mixed VKC had paired samples of tears and serum collected for IgE estimation. Samples were also collected from 14 healthy controls without a history of atopic disease.

\section{Definition of $V K C$ types}

Limbal VKC was distinguished from palpebral VKC by the development of papillae at the limbus without giant papillary formation on the tarsal conjunctiva. The palpebral form was distinguished by giant papillae on the upper tarsal conjunctiva without limbal papillae. Patients showing both giant papillae and limbal papillae were classified as mixed. Although Trantas's dots are commonly associated with limbal papillae they were not considered pathognomonic of limbal VKC because they have been frequently reported at other sites.

\section{Collection of samples for IgE estimation}

Blood was collected by venepuncture into plain sterile tubes and tears with cellulose sponges before separation and storage at -70 degrees $\mathrm{C}$ as previously described. ${ }^{8}$

\section{IgE estimation}

IgE estimation was carried out on all samples at the end of the study. Total IgE was measured by a micro paper radioimmunosorbent test (PRIST) and specific IgE to grass pollens, cat dander and house dust mite by a micro radioallergosorbent test (RAST) as described previously. ${ }^{9}$ The PRIST assay utilises anti-IgE coated paper discs to fix IgE in the sample, RAST uses allergen coated paper discs, which is subsequently detected with ${ }^{125} \mathbf{I}$ anti-IgE. The micro PRIST and RAST differ from the conventional tests by being miniaturised. With these assays as little as $5 \mu \mathrm{l}$ of sample can be used without loss of sensitivity. ${ }^{9}$ The normal range of serum IgE in our laboratory is $2-100 \mathrm{Iu} / \mathrm{ml}$. Similarly wide interindividual variation in total tear IgE levels have been shown; $;^{10.11}$ as there are no established norms for these levels, or for levels of specific IgE in serum or tears, we have not used a cut off but recorded all patients with measurable levels. The specific activity ratio of PlattsMills was used to determine the proportion of specific antibody locally produced by conjunctival and lacrimal tissue. ${ }^{12}$

\section{Statistics}

Qualitative data were analysed with Fisher's exact test or the Chi square test and quantitative data by the Kruskal Wallis one-way analysis of variance (ANOVA) for multiple variables and the Mann Whitney $U$ test for two variables.

\section{Results}

Table I shows the results of the comparison of the clinical characteristics of the three groups. There was no statistically significant difference in the age of the patients in each group or in the age of the patients at the onset of the disease. Eighty-seven (78 per cent) of all patients developed the disease before the age of 16 years. For the remaining criteria there were significant differences between limbal and palpebral or mixed disease, with a preponderance of females with limbal VKC $(p=0.0157)$, Caucasians with palpebral and mixed VKC $(\mathrm{p}=<0.0001)$, subjects with a history of other atopic diseases in palpebral and mixed VKC $(\mathrm{p}=0.0329)$ and a shorter follow up period for limbal VKC $(p=0.0039)$. Corneal scarring and loss of vision were recorded almost exclusively in patients with palpebral or mixed disease $(\mathrm{p}=<0.0001)$ occurring in only one patient with limbal VKC and 50 (47 per cent) with palpebral and mixed VKC of whom 24 (27 per cent) lost vision. 
Table I Comparison of the clinical characteristics of VKC sub-groups in the study population

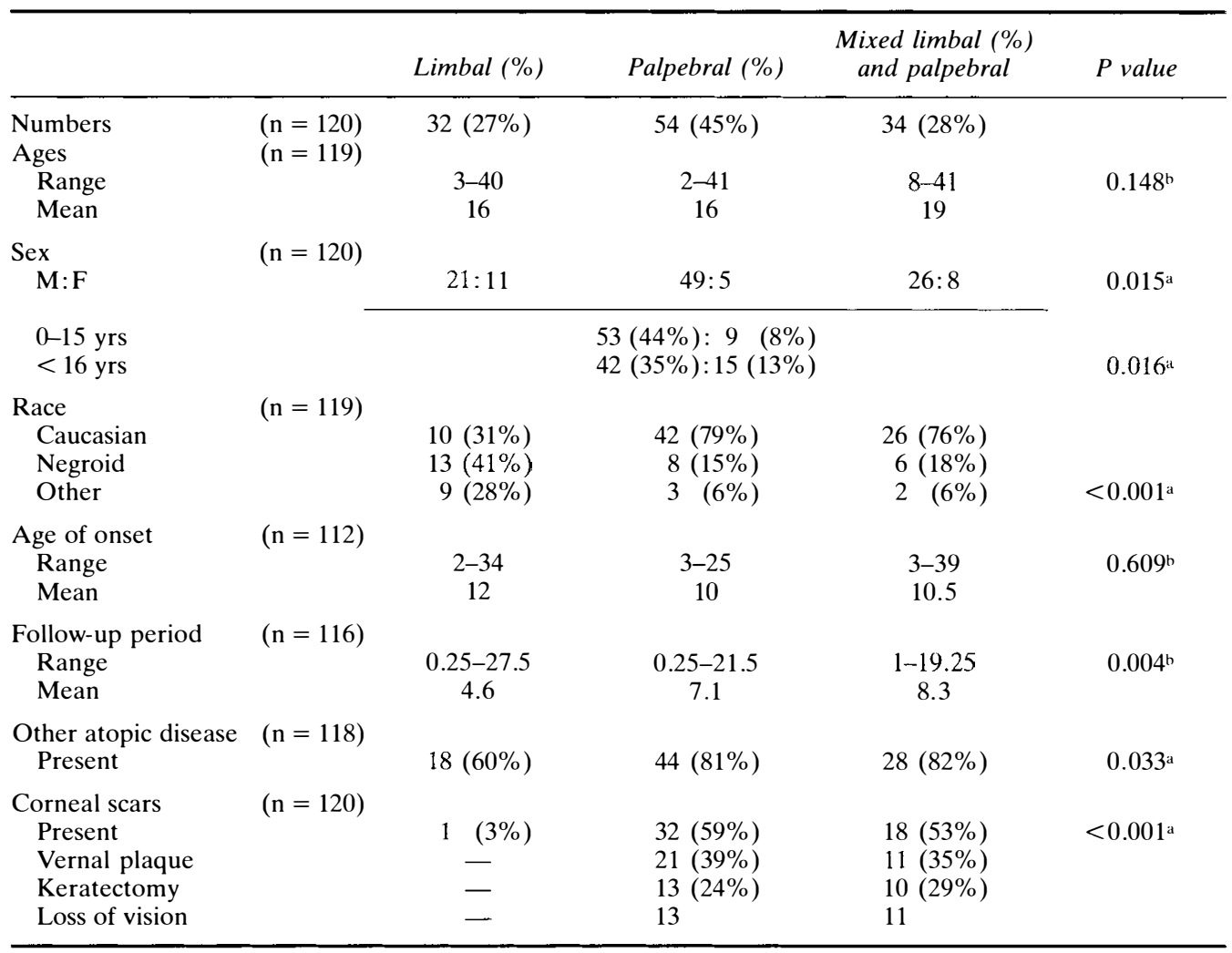

a Chi square test.

${ }^{\mathrm{b}}$ Kruskal Wallis one way analysis of variance.

Scarring resulted from either macroerosion or vernal plaque. Twenty-two eyes (21 patients) with palpebral $\mathrm{VKC}$ had plaques requiring 13 superficial keratectomies (for failure to epithelialise ${ }^{14}$ ) and 12 eyes (11 patients) with mixed VKC also developed plaque requiring 10 superficial keratectomies.

Table II shows that there was no difference in the proportion of patients with limbal and palpebral or mixed disease who had elevated levels of total serum IgE (normal range $2-100 \mathrm{Iu} / \mathrm{ml}$ ) or measurable levels of total $\mathrm{IgE}$ in tears and specific IgE in either tears or serum. The proportions with elevated values were higher than those of the controls except for tear specific IgE to cat and mite where the numbers were small. Similarly there was no significant difference in the absolute levels of both total and specific IgE although there was a trend towards higher levels in the subjects with palpebral disease. The specific activity ratio showed evidence of local production in $11 / 13$ for grass, $2 / 4$ for cat and $5 / 5$ for dust mite.

\section{Discussion}

\section{Clinical characteristics}

Vernal keratoconjunctivitis is a rare condition in most northern countries although it is relatively common in Africa, the Mediterranean, Central and South America. It typically develops in teenage males and resolves after a 2-10 year course. ${ }^{13.5 .7}$ The reasons for this have been addressed infrequently since Beigleman stated in 1950 that no firm conclusion on the incidence of minor endocrinopathies could be reached. ${ }^{1}$ One more recent series of experimental and clinical studies has supported the proposal that the 


\begin{tabular}{|c|c|c|c|c|c|c|}
\hline & \multicolumn{3}{|c|}{ Serum (\%) } & \multicolumn{3}{|c|}{ Tear (\%) } \\
\hline & Limbal & $\begin{array}{l}\text { Palpebral } \\
\text { or mixed }\end{array}$ & Control & Limbal & $\begin{array}{l}\text { Palpebral } \\
\text { or mixed }\end{array}$ & Control \\
\hline \multicolumn{7}{|l|}{ Total IgE } \\
\hline $\mathrm{n}$ & 10 & 17 & 14 & 10 & 15 & 14 \\
\hline $\mathrm{n}>100 \mathrm{Iu} / \mathrm{ml}$ & $9(90 \%)$ & $15(88 \%)$ & 0 & & & \\
\hline n measurable & & & & $7(70 \%)$ & 15 & $3(21 \%)$ \\
\hline Range (Iu/ml) & $16-35720$ & $41-75800$ & $7-50$ & $0-1090$ & $5-9651$ & $7-13$ \\
\hline Median & 1425 & 1130 & 28.5 & 8.5 & 48 & 0 \\
\hline Mean & 8146.9 & 7032.5 & 32.4 & 128.2 & 767.5 & 2.07 \\
\hline SD & 12821.7 & 18426.0 & 25.4 & 339.9 & 2466.58 & 4.29 \\
\hline \multicolumn{7}{|l|}{ Specific $\operatorname{Ig} E^{\mathrm{b}}$} \\
\hline $\mathrm{n}$ & 10 & 17 & 14 & 10 & 15 & 14 \\
\hline n measurable & $9(90 \%)$ & $16(94 \%)$ & $4(29 \%)$ & $6(60 \%)$ & $11(73 \%)$ & $2(14 \%)$ \\
\hline Range (u/ml) & 0-1901 & 0-92603 & $0-50$ & $0-4130$ & $0-401$ & $0-80$ \\
\hline Median & 379 & 439 & 0 & 16.5 & 31 & 0 \\
\hline Mean & 619.3 & 6506 & 6.8 & 479.5 & 77.6 & 7.1 \\
\hline $\mathrm{SD}$ & 662.9 & 23260.2 & 14.2 & 1289.6 & 115.5 & 21.6 \\
\hline \multicolumn{7}{|l|}{ Cat } \\
\hline $\mathrm{n}$ & 10 & 17 & 14 & 10 & 16 & 14 \\
\hline n measurable & 10 & 17 & $4(29 \%)$ & $2(20 \%)$ & $3(19 \%)$ & $1(7 \%)$ \\
\hline Range $(\mathrm{u} / \mathrm{ml})$ & $0-1772$ & $30-979$ & $7-315$ & $0-38$ & $0-275$ & 6 \\
\hline Median & 109 & 131 & 18 & 0 & 0 & 0 \\
\hline Mean & 343.6 & 259.2 & 43.7 & 4.7 & 31.1 & 0.4 \\
\hline SD & 540.2 & 273.6 & 82 & 12 & 79.9 & 1.6 \\
\hline \multicolumn{7}{|l|}{ Mite } \\
\hline $\mathrm{n}$ & 10 & 17 & 14 & 9 & 16 & 14 \\
\hline n measurable & $9(90 \%)$ & $14(82 \%)$ & $2(14 \%)$ & $1(11 \%)$ & $3(19 \%)$ & $1(7 \%)$ \\
\hline Range (u/ml) & $0-608$ & $0-1558$ & $0-196$ & 106 & $0-653$ & 941 \\
\hline Median & 147.5 & 49 & 0 & 0 & 0 & 0 \\
\hline Mean & 206.1 & 161.9 & 14.4 & 11.7 & 65.4 & 67.2 \\
\hline SD & 185.8 & 367.3 & 52.3 & 35.3 & 178.5 & 251.5 \\
\hline
\end{tabular}

Statistical analysis

There was no difference in the proportions of subjects with elevated or measurable IgE between limbal and palpebral or mixed VKC for total or specific IgE in tears or serum at the $1 \%$ level. Compared with the controls a higher proportion of VKC subjects had elevated IgE levels at the $1 \%$ level except for tear IgE against cat and mite for which differences were not significant. The absolute levels of IgE were significantly higher in the VKC subjects than controls at the $1 \%$ level but there were no differences between limbal and palpebral VKC. Tear IgE to cat and mite were not analysed because the numbers were small.

a Measured by PRIST in Iu/ml.

${ }^{\mathrm{b}}$ Measured by RAST in $\mathrm{u} / \mathrm{ml}(1 \mathrm{u} / \mathrm{ml}=$ approx. $0.1 \mathrm{ng} / \mathrm{ml})$.

development of the disease was associated with hypogonadism and hypoadrenalism in males but not in females. Part of their clinical evidence was based on the observation that the disease was more prevalent in males under the age of 15 years but in females above 16 years $^{13}$ confirming some previous observations. ${ }^{1}$ In our series although the proportion of females was higher above the age of 16 years the difference was not statistically sig- nificant. However the significantly higher proportion of females with limbal disease found in our series has not been remarked on in the recent literature. The preponderance of limbal VKC in blacks has frequently been noted before ${ }^{1.2 .57}$ but attention has not been drawn to the difference in the prevalence of the limbal and palpebral forms of $\mathrm{VKC}$ in different races in a single centre population. This provides strong evidence for genetic rather than 
environmental factors in determining the development of the different forms of the disease. Further evidence for the importance of genetic factors, which also implies a difference in the immunopathology of the different forms, is our finding that significantly fewer patients with limbal VKC had associated atopic diseases. The shorter follow-up period in the limbal VKC group suggests that this form of the disease may have a shorter duration than the palpebral form in our population. These findings infer a markedly different response to similar stimuli in genetically different groups and it may be an over simplification to consider limbal, palpebral and mixed VKC as different expressions of the same disease..$^{1-7}$

\section{Clinical signs}

\section{Limbal $V K C$}

In our study limbal VKC was distinguished from palpebral $\mathrm{VKC}$ by the development of papillae at the limbus without giant papillary formation on the tarsal conjunctiva although a papillary reaction with infiltrate was present. Trantas's dots are commonly associated with limbal papillae but are not considered to be pathognomonic of limbal VKC as they have been frequently recorded from the bulbar and palpebral conjunctiva. Pseudogerontoxon, ${ }^{4.5}$ a term coined by Beigelman, is common in severe limbal disease with a similar appearance to arcus senilis although subtle differences have been described. ${ }^{1}$ Severe keratopathy resulting from central extension of limbal vegetations has been reported in the literature ${ }^{1.2}$ but is now rarely seen due to the advent of more effective treatment.

\section{Palpebral and Mixed $V K C$}

In the palpebral form there are giant papillae on the upper tarsal conjunctiva. During exacerbations of the disease corneal involvement is common and begins with a punctate epithelial keratopathy to which abnormal mucous adheres. This may be followed by the development of macroerosion that is often complicated by a vernal plaque that involves Bowman's membrane and interferes with corneal re-epithelialisation. ${ }^{14}$ Thirty-two patients in our series with palpebral or mixed VKC developed plaque whereas none of the patients with limbal VKC had this complication. The absence of this type of keratopathy in limbal disease may be because there is less associated inflammatory activity in the palpebral conjunctiva. It is likely that these corneal manifestations are due to the toxic effects of inflammatory products such as eosinophil major basic protein rather than the mechanical effect of the giant papillae..$^{14-16}$ The mixed form of the disease shares the characteristics of both limbal and palpebral forms.

Histopathology in limbal and palpebral $V K C$ The light microscopic findings in VKC have been well described ${ }^{1,2,17}$ and have not suggested that any differences might exist in the immunopathology of limbal and palpebral VKC. The principal findings have been of infiltration of the conjunctival substantia propria by lymphocytes, plasma cells, neutrophils, histiocytes, eosinophils and fibroblasts with hyperplasia and hyalinisation of collagen. The epithelium shows both proliferative and degenerative changes and also contains these inflammatory cells. One group has also noted basophil infiltrates in palpebral vernal conjunctivitis. ${ }^{18.19}$ Mast cells are more numerous during remissions but plasma cells and lymphocytes less so. ${ }^{17}$ Giant papillae consist of dense fibrous tissue containing the same population of inflammatory cells already described. The main difference between limbal and palpebral VKC is the enormous epithelial overgrowth in limbal VKC with solid downward extensions of epithelial plugs often incorporating 30-40 layers of cells. ${ }^{1.2}$ Electron microscopic findings have been carried out on palpebral but not limbal cases. ${ }^{18.19}$ These studies have added to the light microscopic findings by showing that the epithelial cells have evidence of greatly increased secretory activity. ${ }^{20}$

It is not surprising that the limbus is involved in VKC as the limbal palisades provide the only true papillary structures in the conjunctiva containing vessels, nerves and lymphatics. ${ }^{21}$ The bulbar conjunctiva presents the same histological picture as the limbal and tarsal findings without the giant papillary hypertrophy, ${ }^{1}$ possibly due to the loose 
attachment of the conjunctiva to the bulbar fascia. This may allow the increase in tissue volume to be distributed evenly rather than in nodules constrained by the firm attachments of the conjunctiva to the underlying structures at the limbus and tarsus.

\section{Immunopathology}

Limbal VKC is one of the atopic diseases of the eye in which Type 1 or anaphylactic hypersensitivity, resulting from IgE mediated mast cell degranulation, is an important pathogenic mechanism. ${ }^{3,5-7}$ The evidence for this is the association of many cases with other atopic diseases; the presence of high densities of mast cells and eosinophils in the conjunctiva; the presence of histamine and eosinophil major basic protein in the tears; elevated levels of total and specific IgE in the tears, where $\operatorname{IgE}$ is locally produced, ${ }^{10.11,22-24}$ and serum of some patients and a response to treatment with the mast cell stabiliser sodium cromoglycate in some cases.

We examined the levels of total and specific IgE levels in VKC and compared limbal with palpebral or mixed VKC. This followed our previous finding that IgE specific antibody production to house dust mite distinguished perennial from seasonal allergic conjunctivitis. ${ }^{8}$ Limbal VKC was compared with the pooled results from patients with palpebral and mixed disease after we had shown that the clinical characteristics of palpebral and mixed disease were very similar compared to limbal VKC. Neither total nor specific IgE levels were different in the two groups of VKC patients, either for the proportions with raised levels, or the absolute levels. For total IgE and most specific IgE the levels were higher in the palpebral group although the differences were not statistically significant. Nearly all the VKC patients had elevated levels of total serum and tear $\mathrm{IgE}$ compared to the control group in which this was rare. These findings are similar to those reported by other authors. ${ }^{22,25}$ In addition the measurable levels of specific serum $\operatorname{IgE}$ for grass, cat and mite antibodies were higher and present more frequently compared to controls and there was evidence of local production in most cases. However only very few of the VKC subjects, not significantly greater than the proportions for controls, had measurable levels of tear specific IgE against cat and mite. The proportions of patients with elevated levels of tear and or serum specific antibodies is higher than that shown by Sompolinsky ${ }^{23,24}$ who has pointed out that the disease is not seasonal in his study area, unlike ours, suggesting that different allergens may be important in different geographic regions.

Several findings suggest that hypersensitivity mechanisms other than Type 1 may be important in some cases of $\mathrm{VKC}$. The presence of patients with VKC who have no personal or family history of atopy ${ }^{3}$ varying from $16-100$ per cent in different reports; ${ }^{1}$ the proportions of patients with positive intradermal skin prick tests varies with most series containing unresponsive patients; $;^{1,26}$ a sub-group of patients with either limbal or palpebral VKC have normal levels of IgE, although only 7 per cent for this series up to 30 per cent have had normal levels in serum and tears in some. ${ }^{27-29}$ These patients may represent a subgroup of VKC with a different immunopathology $y^{27}-30$ and in whom treatment directed at $\operatorname{IgE}$ stimulus dependant mechanisms, such as sodium cromoglycate, may be of little value. ${ }^{28.30}$ In this sub-group it is possible that IgG antibodies may have reaginic (Type 1) activity. ${ }^{31}$ However the role of these antibodies remains controversial and has not been investigated in VKC. Further evidence for an alternative immunopathology derives from histological and immunohistochemical studies. Basophils have been identified in large numbers in palpebral VKC which, together with disruption of vascular endothelial cells, indicates that a delayed basophil hypersensitivity mechanism may be important. ${ }^{17,18}$ The evidence for a delayed hypersensitivity response in animal models is conflicting with some studies showing recruitment of both eosinophils and basophils ${ }^{32}$ and others, using different induction methods and histological techniques, showing an eosinophil response alone. ${ }^{33,34}$ Only one similar study has been carried out in limbal $\mathrm{VKC}$ in which it is interesting that immunohistochemistry did not find basophils present in large numbers although the findings did suggest the presence of delayed type hyper- 
sensitivity in addition to anaphylactic hypersensitivity. ${ }^{35}$

Recent studies showing heterogeneity in the effector cell populations in Type 1 mediated diseases may be relevant to differences in VKC sub-groups. It has been shown that at least two subclasses of mast cells exist in humans; these can be recognised by their neutral protease composition or their histochemical characteristics. ${ }^{36,37}$ This heterogeneity reflects that found in rodents which have distinct connective tissue and mucosal populations of mast cells. These differences are reflected in a functional heterogeneity in which the profiles of responsiveness to antiallergic agents differ. ${ }^{36,38}$ The question of differential activation, differentiation, and proliferation of human mast cell types in different tissues and different clinical conditions may be important to understanding differences in the clinical characteristics and response to therapy of allergic diseases. ${ }^{37}$ Mast cell heterogeneity is only one aspect of this problem and eosinophil heterogeneity and variations in the role of other immune effector cells must be considered..$^{39,40}$

\section{Conclusion}

Our study provides some evidence for considering that limbal vernal may be a different disease entity from palpebral or mixed vernal as, in our multiracial single centre population, these groups were significantly different in terms of race, sex, atopic history and time course. These differences were not expressed in terms of either total or specific IgE production in this study and are more likely to be the result of other possible variations in the inflammatory response and the relative importance of different hypersensitivity responses. Other studies suggest that in many individuals with VKC there may be both anaphylactic IgE and cell mediated hypersensitivity. In addition they suggest there is a sub-group of $\mathrm{VKC}$ patients who do not have evidence of a Type 1 hypersensitivity in which IgE is a major mediator. An IgG mediated Type 1 response may occur or more probably different types of delayed hypersensitivity may be important. In recent years the different types of VKC have been thought to have a similar pathogenesis. One recent study of the cytology and immu- nohistochemistry in limbal $\mathrm{VKC}^{35}$ has shown different immunopathology from somestudies of palpebral VKC. ${ }^{17,18}$ Also recent studies of effector cell heterogeneity in other diseases suggest that differences in the immunopathogenesis may exist that could not have been identified with previous techniques. Functional heterogeneity in effector cell populations may explain differences both in the clinical characteristics and the response to different drugs. As the number of available drugs increases and their action becomes more specific, understanding the pathogenesis of these diseases at the cellular level will be necessary. In any further studies, particularly of the immunopathology of $\mathrm{VKC}$, it will be important to distinguish clinical types before analysis. In addition, the shorter course of limbal VKC and its lower morbidity compared to palpebral VKC in our population provides useful prognostic information for the management of this chronic disabling ocular disorder.

We thank Roger Buckley FRCS for his help and for access to his patients and their records.

\section{References}

${ }^{1}$ Beigelman MN: Vernal conjunctivitis. Los Angeles. University of Southern California Press, 1950.

2 Duke-Elder S: Vol VIII. Diseases of the outer eye. Part 1. London. Henry Kimpton, 1965, 475-93.

${ }^{3}$ Allansmith MR: Vernal conjunctivitis. In Duane TD ed. Vol 4. Chap 9. Clinical Ophthalmology. New York. Harper and Row, 1980, 6.

${ }^{4}$ Allansmith MR and Abelson MB: Ocular allergies. In Smolin G, Thoft RA Eds. Chap 6. The Cornea; scientific foundations and clinical practice. Boston, Little Brown and Co. 1983, 26.

${ }^{5}$ Smolin G and O'Connor R: Ocular Immunology. Philadelphia, Lea and Febiger 1981, 137.

${ }^{6}$. Easty DL: External ocular disease in atopic patients. In Easty DL, Smolin G. eds. Chap 9. External eye disease. London, Butterworth and Co., 1985, 247.

${ }^{7}$ Buckley RJ: Vernal keratoconjunctivitis. Int Ophthalmol Clin 1989, 29: 303-8.

${ }^{8}$ Dart JKG, Buckley RJ, Monnickendan M, Prasad J: Perennial allergic conjunctivitis: definition, clinical characteristics and prevalence. A comparison with seasonal allergic conjunctivitis. Trans Ophthalmol Soc UK 1986, 105: 513-20.

${ }^{9}$ Kemeny DM and Richards D: Increased speed and sensitivity of a micro radioallergosorbent test (MRAST). J Immun Methods 1988, 108: 105-13.

10 Aalders-Deenstra V, Kok PTM, Bruynzeel PLB: Measurement of total IgE antibody levels in lacrimal fluid of patients suffering from atopic and non-atopic eye disorders. Evidence for local IgE 
production in atopic eye disorders. $\mathrm{Br} J$ Ophthalmol 1985, 69: 385-8.

${ }^{11}$ Insler MS, Lim JM, Queng JT, Wanissorn C, McGovern JP: Tear and serum IgE concentrations by Tandem-R IgE immunoradiometric assay in allergic patients. Ophthalmology 1987, 94: 945-8.

12 Platts-Mills TAE: Local production of $\operatorname{IgG}, \operatorname{Ig} A$ and $\mathrm{IgE}$ antibodies in grass pollen hay fever. J Immunol 1979, 122: 2218-24.

${ }^{13}$ Aoki H: Relations of eye diseases with thymus and endocrine glands-especially with regard to experimental allergic conjunctivitis and vernal conjunctivitis. Acta Soc Ophthalmol Jap 1968, 72: 1949-65.

${ }^{14}$ Buckley RJ: Vernal keratopathy and its management. Trans Ophthalmol Soc UK 1981, 101: 234-8.

15 Udell IJ, Gleich GJ, Allansmith MA, Ackerman SJ, Abelson MB: Eosinophil granule major basic protein and Charcot-Leyden crystal protein in human tears. Am J Ophthalmol 1981, 92: 824-8.

${ }^{16}$ Gleich JG, Frigas E, Loegering DA, Wassom DL, Steinmuller D: Communication. Cytotoxic properties of the eosinophil major basic protein. $J$ Immunol 1979, 123: 2925-7.

${ }^{17}$ Morgan G: The pathology of vernal conjunctivitis. Trans Ophthalmol Soc UK 1971, 91: 467-78.

${ }_{18}$ Collin HB and Allansmith MR: Basophils in vernal conjunctivitis in humans: an electron microscopic study. Invest Ophthalmol Vis Sci 1977, 16: 858-64.

${ }^{19}$ Allansmith MR, Baird RS, Greiner JV: Vernal conjunctivitis and contact lens-associated giant papillary conjunctivitis compared and contrasted. Am J Ophthalmol 1979, 87: 544-55.

${ }^{20}$ Takakusaki I: Fine structure of the human palpebral conjunctiva with special reference to the pathological changes in vernal conjunctivitis. Arch Histol Jap 1969, 30: 247-82.

${ }^{21}$ Hogan MJ, Alvarado JA, Weddell JE: Histology of the human eye. Philadelphia. WB Saunders 1971, 119.

22 Samra Z, Zavaro A, Barishak Y, Sompolinsky D: Vernal keratoconjunctivitis: the significance of immunoglobulin E levels in tears and serum. Int Archs Allergy Appl Immunol 1984, 74: 158-64.

${ }^{23}$ Sompolinsky D, Samra Z, Zavaro A, Barishak Y: Allergen-specific immunoglobulin $\mathrm{E}$ antibodies in tears and serum of vernal conjunctivitis patients. Int Archs Allergy Appl Immunol 1984, 75: 31721.

${ }^{24}$ Ballow $\mathbf{M}$ and Mendelson L: Specific immunoglobulin $\mathrm{E}$ antibodies in tear secretions of patients with vernal conjunctivitis. J Allergy Clin Immunol 1980, 66: 112-8.

25 Allansmith MR, Hahn GS, Simon MA: Tissue, tear and serum IgE concentrations in vernal conjunctivitis. Am J Ophthalmol 1976, 81: 506-11.

${ }^{26}$ Frankland AW and Easty D: Vernal kerato-conjunctivitis: an atopic disease. Trans Ophthalmol Soc UK 1971, 91: 479-82.
27 Zavaro A, Baryishak YR, Samra Z, Sompolinsky D: Extrinsic and idiopathic vernal keratoconjunctivitis? two cases with a dissimilar immunopathology. Br J Ophthalmol 1983, 67: 742-5.

${ }^{28}$ Baryishak YR, Zavaro A, Monselise M, Samra Z, Sompolinsky D: Vernal keratoconjunctivitis in an Israeli group of patients and its treatment with sodium cromoglycate. Br J Ophthalmol 1982, 66: 118-22.

${ }^{29}$ Easty DL, Birkinshaw M, Merrett T, Merrett J, Madden P: Immunology of vernal disease. In Pepys J, Edwards AM. The mast cell; its role in health and disease. London. Pitman Medical Publishing Co. 1979, 493-502.

${ }^{30}$ Foster CS: The cromolyn sodium collaborative study group. Evaluation of topical cromolyn sodium in the treatment of vernal keratoconjunctivitis. Ophthalmology 1988, 95: 194-201.

${ }^{31}$ Ballow M, Mendelson L, Donshik P, Rooklin A, Rapacz P: Pollen-specific IgG antibodies in the tears of patients with allergic-like conjunctivitis. $J$ Allergy Clin Immunol 1984, 73: 376-80.

${ }^{32}$ Mann LE, Cornell-Bell AH, Marten-Ellis C, Allansmith MR: Conjunctival basophil hypersensitivity lesions in guinea pigs. Analysis of upper tarsal epithelium. Invest Ophthalmol Vis Sci 1986, 27: $1255-60$.

${ }^{33}$ Khatami M, Donnelly JJ, John T, Rockey JH: Vernal conjunctivitis. Model studies in guinea pigs immunised topically with fluoresceinyl ovalbumin. Arch Ophthalmol 1984, 102: 1683-88.

${ }^{34}$ Darougar S and St C Dwyer R: Models of immediate and delayed hypersensitivity in the guinea pig conjunctiva. Trans Ophthalmol Soc UK 1971, 91: $451-61$.

${ }_{35}$ Asrar AM, Geboes K, Missotten L, Emarah MH, Maudgal PC, Desmet V: Cytological and immunohistochemical study of the limbal form of vernal keratoconjunctivitis by the replica technique. Br J Ophthalmol 1987, 71: 867-72.

${ }^{36}$ Befus D, Goodacre R, Dyck N, Bienenstock J: Mast cell heterogeneity in man. I. Histologic studies of the intestine. Int Archs Allergy Appl Immunol 1985, 76: 232-6.

${ }^{37}$ Irani AA, Schechter NM, Craig SS, DeBlois G, Schwartz LB: Two types of human mast cells that have distinct neutral protease compositions (tryptase/chymotryptic protease). Proc Natl Acad Sci USA 1986, 83: 4464-8.

${ }^{38}$ Pearce FL: Functional differences between mast cells from various locations. In Befus $\mathrm{AD}$, Bienenstock J, Denburg JA, eds. Mast cell differentiation and heterogeneity. New York: Raven Press, 1986, 215-22.

${ }^{39}$ Butrus SI, Leung DYM, Gellis S, Baum J, Kenyon $\mathrm{KR}$, Abelson MB: Vernal conjunctivitis in the hyperimmunoglobulinemia E syndrome. Ophthalmology 1984, 91: 1213-6.

${ }^{40}$ Rothenberg ME, Owen WF, Stevens RL: Mast cells and eosinophils. Int Ophthalmol Clin 1989, 29: 267-74. 